Instituto Internacional de Investigación y Desarrollo Tecnológico Educativo INDTEC, C.A.

DOI: https://doi.org/10.29394/Scientific.issn.2542-2987.2021.6.21.13.252-266

OAI-PMH: http://www.indteca.com/ojs/index.php/Revista Scientific/oai

Ensayo Original / Original Essay

\title{
Retorno presencial a universidades en México y consecuencias de la salud mental por pandemia
}

\author{
Autores: Diego Alvarado Melitón \\ Hospital Psiquiátrico Fray Bernardino Álvarez, HPFBA \\ ocupacional fray@outlook.com \\ Ciudad de México, México \\ https://orcid.org/0000-0002-4116-885X \\ Sara Elena Berra Mondragón \\ Universidad Tres Culturas, UTC \\ saraelena berra@hotmail.com \\ Toluca, México \\ https://orcid.org/0000-0001-5895-2897
}

\section{Resumen}

En los primeros días de cuarentena se notaba escenarios de incertidumbre, momentos de mucho estrés, desmotivación, realmente parecía incierto que se lograran los objetivos educativos en una modalidad a distancia, pero también es cierto que poco a poco se pudo innovar en los procesos de aprendizaje para despejar las dudas de este reto educativo. A pesar de implementar recursos tecnológicos, las consecuencias en la salud mental de los actores sociales de la educación superior fueron más que evidentes antes, durante y actualmente por pandemia, como lo mencionan Cuenca, Robladillo, Meneses y Suyo-Vega (2020), por tal motivo se toman medidas sanitarias y apoyo socioemocional en las universidades públicas y privadas de acuerdo con PinargoteBaque y Cevallos-Cedeño (2020), así como para evitar la propagación del virus y disminuir los trastornos mentales, teniendo en cuenta que el retorno presencial debe ser de manera voluntaria, escalonada o por necesidades practicas educativas. El propósito en este ensayo es destacar las consecuencias de la salud mental y la intervención oportuna en docentes y alumnos universitarios ante el regreso presencial por medio de profesionales especializados para afrontar las repercusiones de la pandemia.

Palabras clave: México; universidad; salud mental; pandemia.

Código de clasificación internacional: 5802.04 - Niveles y temas de educación.

Cómo citar este ensayo:

Alvarado, D., \& Berra, S. (2021). Retorno presencial a universidades en México y consecuencias de la salud mental por pandemia. Revista Scientific, 6(21), 252-266, e-ISSN: 2542-2987. Recuperado de: https://doi.org/10.29394/Scientific.issn.2542-2987.2021.6.21.13.252-266

Fecha de Recepción: 13-03-2021
Fecha de Aceptación: 02-07-2021
Fecha de Publicación: 05-08-2021 
Instituto Internacional de Investigación y Desarrollo Tecnológico Educativo INDTEC, C.A.

DOI: https://doi.org/10.29394/Scientific.issn.2542-2987.2021.6.21.13.252-266

OAI-PMH: http://www.indteca.com/ojs/index.php/Revista Scientific/oai

Ensayo Original / Original Essay

\title{
Face-to-face return to universities in Mexico and consequences of mental health due to pandemic
}

\begin{abstract}
In the first days of quarantine there were scenarios of uncertainty, moments of great stress, demotivation, it really seemed uncertain that the educational objectives would be achieved in a distance mode, but it is also true that little by little it was possible to innovate in the learning processes to clear the doubts of this educational challenge. Despite implementing technological resources, the consequences on the mental health of social actors in higher education were more than evident before, during and currently due to a pandemic, as mentioned by Cuenca, Robladillo, Meneses and Suyo-Vega (2020), for For this reason, health measures and socio-emotional support are taken in public and private universities in accordance with Pinargote-Baque and Cevallos-Cedeño (2020), as well as to prevent the spread of the virus and reduce mental disorders, taking into account that face-to-face return It must be voluntary, staggered or for practical educational needs. The purpose of this essay is to highlight the consequences of mental health and the timely intervention in teachers and university students in the face of face-to-face return through specialized professionals to face the repercussions of the pandemic.
\end{abstract}

Keywords: Mexico; university; mental health; pandemic.

International classification code: 5802.04 - Levels and subjects of education.

How to cite this essay:

Alvarado, D., \& Berra, S. (2021). Face-to-face return to universities in Mexico and consequences of mental health due to pandemic. Revista Scientific, 6(21), 252-266, e-ISSN: 2542-2987. Recovered from: https://doi.org/10.29394/Scientific.issn.2542-2987.2021.6.21.13.252-266

Date Received: 13-03-2021
Date Acceptance:

02-07-2021
Date Publication: 05-08-2021 


\section{Introducción}

El presente ensayo tiene como finalidad dar a conocer la situación actual en la que se encuentran las instituciones educativas en México después de un largo periodo de inactividad escolar debido al aislamiento social que se impuso como consecuencia de la pandemia de COVID-19, ante tal posible retorno presencial de los actores sociales de la educación, se deben tomar en cuenta que las estructuras físicas deberán ser adaptadas a las necesidades sanitarias actuales impuestas por la situación de la pandemia de acuerdo al semáforo epidemiológico en color verde impuesto por el gobierno federal.

Como es bien sabido, durante el aislamiento social se presentaron varios problemas de salud mental que afectaron tanto a docentes como alumnos por un cambio tan radical en el proceso evolutivo educativo, así como el uso de las tecnologías de la información y plataformas educativas que conllevaron a detonar problemas emocionales, cognitivos y sociales que actualmente persisten, dichos síntomas que presentan los actores sociales de la educación, posiblemente no se les brinda la atención necesaria ante tal regreso a las instituciones educativas para nivel superior.

Por otro lado, el personal docente de cada institución académica ya sea publica o particular deberá tener el conocimiento adecuado para situarse nuevamente en su ámbito de enseñanza tradicional y adaptarse para sobrellevar el ciclo escolar presencial con las medidas sanitarias impuestas y a la vez los problemas emocionales que se presenten en sus alumnos, las consecuencias que serán observadas principalmente pueden ser; sentimientos de tristeza, apatía, enojo, aislamiento, frustración, ansiedad, estrés, etc., además de tener en cuenta que los brotes del virus pueden seguir presentándose aunque ya se haya aplicado la inmunización del personal y alumnos.

Además, se debe colaborar con profesionales especializados en el ámbito psicológico y psiquiátrico, que permitan detectar emociones durante el 
transcurso del ciclo escolar presencial, favoreciendo una intervención satisfactoria y siendo este un proceso de colaboración con el personal directivo de las instituciones educativas para brindar los recursos y apoyos necesarios ante la repercusión y el impacto de la salud mental en su personal.

Ante el retorno presencial a las universidades públicas y privadas es recomendable implementar estrategias de afrontamiento y contención emocional, por lo tanto, el objetivo de este ensayo, es destacar las consecuencias de la salud mental para los actores de la educación universitaria, así como la intervención oportuna mediante la implementación de monitoreos y soporte socioemocional en las instituciones y evitar situaciones adversas en la salud mental de docentes y alumnos, ante tal regreso a las universidades.

\section{Desarrollo}

Con respecto al inicio de la pandemia del virus COVID-19 en México para el sector educativo, se adelantaron las vacaciones de semana santa para evitar que se propagara dicho virus y por parte de la Secretaría de Educación Pública (SEP, 2020): se emitió un acuerdo número 02/03/20, en el cual, se suspendieron clases del 23 de marzo al 17 de abril del año 2020, dicho acuerdo realizado involucraba a las instituciones de educación preescolar, primaria, secundaria, normal, medio superior y superior, por lo que conllevo a un cierre de las instituciones de educación y se realiza la sustitución de los espacios físicos o aulas físicas por la implementación de plataformas digitales hasta que finalice la pandemia.

En cuanto a las instituciones educativas ya sean de ámbito particular o público y debido a su ubicación territorial (urbana o rural), han sido descuidadas en mantenimiento, por lo que requieren ser atendidas de manera inmediata para un posible retorno presencial de los actores sociales de la educación, sin dejar de lado que las desigualdades sociales son muy notorias 
ante tal regreso, debido a las carencias y apoyos que se obtendrán por parte de las autoridades que rigen al sistema educativo, siendo más beneficiadas aquellas instituciones privadas que gozan de recursos económicos y dejando de lado las instituciones públicas con mínimos apoyos o en su caso en la zona rural.

Cabe destacar que para implementar y adaptar las medidas sanitarias en las instituciones educativas conlleva un proceso riguroso donde se toma en cuenta los recursos materiales, técnicos, humanos, financieros y administrativos, siendo una prioridad retomar el ciclo escolar y el proceso de enseñanza-aprendizaje presencial, por lo cual se lleva a cabo la implementación de las guías de salud para el retorno seguro a actividades semipresenciales a nivel superior, además de tener otras estrategias en los espacios físicos, pero sin dejar de lado el apoyo socioemocional en los docentes y alumnos a la hora de reincorporarse a los escenarios principales para su adaptación presencial y social.

Por esto se da a la tarea de cumplir con las medidas de seguridad e higiene en las aulas físicas de las instituciones y evitar riesgos de contagios por el virus COVID-19, entre las medidas que se han considerado en dichas guías de salud son; sanitización y limpieza de aulas, uso de cubrebocas, distanciamiento físico, lavado de manos, filtros de ingreso, señalización de espacios, suministros de alcohol en gel, sensores de temperatura, apoyo socioemocional para docentes y estudiantes, sin embargo hasta el momento este retorno presencial es voluntario y de forma escalonada conforme a las indicaciones de la SEP y a los congresos técnicos de las universidades del sector público y privado.

Por tal motivo, las universidades difieren en cuanto al regreso de sus estudiantes a las clases presenciales debido a que son autónomas y poseen la capacidad de tomar sus propias decisiones ante tal situación, considerando que algunas instituciones harán acto de presencia para su personal y 
alumnado de acuerdo al cambio de semáforo epidemiológico al color verde, algunas con probabilidad para el día 07 de junio del 2021 en la Ciudad de México y en el Estado de México con fecha del 14 de junio, siguiendo los protocolos de regreso seguro, además de tomar en cuenta que su personal docente y alumnos deben estar vacunados, además de seguir en la duda de si regresar o no hacerlo por los nuevas variantes del virus.

En particular, para algunas universidades, la asistencia presencial es con la finalidad de realizar actividades prácticas, experimentales y exámenes, se toma en cuenta el cambio del semáforo epidemiológico a color verde para un regreso seguro, además de tener en cuenta las medidas sanitarias y estratégicas que se hayan decidido por su consejo técnico y tomando en cuenta que el porcentaje para acudir a las instalaciones educativas es del 30 por ciento, por otro lado, algunas instituciones de educación superior han decidido concluir su ciclo escolar mediante la modalidad a distancia y probablemente seguir con el mismo modelo para el siguiente ciclo escolar.

Debido al cambio de color verde en el semáforo epidemiológico, el regreso a clases presenciales se ha de valorar la integridad de la salud mental de los actores sociales de la educación, debido a las secuelas que se han presentado a lo largo del periodo de la pandemia y cuyos efectos son reflejados en emociones negativas, aunque se sabe que en alumnos universitarios no únicamente en México, también en otros países se hacían evidentes desde antes de la pandemia, algunos síntomas de enfermedad mental, como lo mencionan Cuenca, Robladillo, Meneses y Suyo-Vega (2020):

En América Latina se tiene el interés de ahondar en el estado de la salud mental del adolescente universitario, Gaete, expresa que los adolescentes, tienen una alta prevalencia de trastornos psiquiátricos siendo los más frecuentes: comportamientos depresivos, conducta suicida, ansiedad, problemas de conducta y déficit en la atención, cognición y aprendizaje. Con frecuencia presentan sentimientos de soledad, dificultad para dormir y menor interacción social 
Instituto Internacional de Investigación y Desarrollo Tecnológico Educativo INDTEC, C.A. DOI: https://doi.org/10.29394/Scientific.issn.2542-2987.2021.6.21.13.252-266

OAI-PMH: http://www.indteca.com/ojs/index.php/Revista Scientific/oai

Ensayo Original / Original Essay

acompañado con el consumo frecuente de tabaco (págs. 689690).

Por otra parte los estudiantes y profesores denotaron una alteración emocional al cambio tan drástico que se presentó al implementar el uso de plataformas educativas de las tecnologías de la información, la repercusión de esta brecha digital fue muy notoria principalmente en los docentes quienes siempre habían usado métodos de enseñanza-aprendizaje tradicionales, sin embargo la afección principal fue para los alumnos universitarios quienes al no tener unas habilidades emocionales desarrolladas fue un tremendo conflicto para su productividad durante el ciclo escolar, considerando que antes de la pandemia ya se tenían antecedentes que reflejaban una mala salud mental como lo señala Alarcón (2019):

En los grupos etarios correspondientes al estudiantado universitario, los síntomas tanto cognitivos como afectivos son interiorizados y se presentan con una mayor intensidad. Son relativamente frecuentes también los trastornos conductuales, conducta sexual promiscua, agresividad, retraimiento, humor fluctuante En este contexto, es conocida la prominencia de depresión y sus variantes nosológicas en la llamada Carga Global de Enfermedad; dentro de ella, se da una variedad de las llamadas conductas suicidas: desde pensamientos de muerte hasta consumación del acto, pasando por franca ideación suicida y una variedad de gestos o actos autodestructivos de reiterada frecuencia e intensidad creciente (págs. 219-220).

Por lo tanto, después del aislamiento y el uso de plataformas educativas para brindar clases en línea se puede desencadenar una oleada de comportamientos inusuales representadas en adicciones digitales por parte del alumnado, teniendo que el termino adicción es enfocado a una alteración de la conducta ante las tecnologías usadas para el proceso de enseñanzaaprendizaje, observadas mediante conflictos a nivel físico, psicológico y social, que pueden afectar de manera paulatina el regreso a clases presenciales, 
Instituto Internacional de Investigación y Desarrollo Tecnológico Educativo INDTEC, C.A. DOI: https://doi.org/10.29394/Scientific.issn.2542-2987.2021.6.21.13.252-266

OAI-PMH: http://www.indteca.com/ojs/index.php/Revista Scientific/oai

Ensayo Original / Original Essay

dicho en palabras de Pinargote-Baque y Cevallos-Cedeño (2020):

Clínicamente se han descrito en la literatura síntomas físicos como: astenia, desnutrición, cefalea, fatiga ocular, tensión y contracturas musculares, insomnio / hipersomnia, sedentarismo, sobrepeso/obesidad, etc. A nivel psicológico destacan: empobrecimiento afectivo, ansiedad, inestabilidad emocional, depresión, inmadurez, problemas de aprendizaje, confusión mundo real imaginario, ira/ agresividad, etc. Finalmente, a nivel social podemos encontrar: aislamiento social, incumplimiento de las obligaciones familiares, académicas, sociales, conflictos en el ámbito familiaracadémico-social, problemas legales, etc. (págs. 526-527).

En cuanto a los docentes académicos se tendrán que adaptar al rezago académico que fueron evidenciados mediante el uso de las plataformas educativas, sumando que también se presentó la deserción de aquellos estudiantes que no contaban con los recursos necesarios, computadora y conexión a internet, sin contar el lugar demográfico y los pocos recursos económicos de las familias que daban el soporte a estos estudiantes, afectando al docente en el aspecto afectivo, laboral y social al tener menos alumnos en sus aulas virtuales pero mayor carga de trabajo.

Entonces, está claro que al tener una mayor exigencia a los docentes con cargas extras de evaluaciones, planeaciones didácticas, revisiones de tareas, etc., y en su momento pocas o escasas competencias digitales, estos actores también sufrieron el impacto del aislamiento social mediante un desgaste físico, cognitivo, emocional y social, como lo afirman Mandernach y Holbeck (2016); Ordoñez y Saltos (2018); Sánchez, et al. (2020), citados por Medina-Guillen, Quintanilla-Ferrufino, Palma-Vallejo y Medina (2021): “en un intento del profesorado para aprender a utilizar estas plataformas deprisa, quizá sin apoyo, soporte técnico y tiempo suficiente, lo que genera sobrecarga laboral" (pág. 3).

En efecto, los docentes presentaban otro problema ya que con 
Instituto Internacional de Investigación y Desarrollo Tecnológico Educativo INDTEC, C.A.

DOI: https://doi.org/10.29394/Scientific.issn.2542-2987.2021.6.21.13.252-266

OAI-PMH: http://www.indteca.com/ojs/index.php/Revista Scientific/oai

Ensayo Original / Original Essay

frecuencia los estudiantes preguntaban; en cada oportunidad que se presentaba, cuándo sería el retorno a las aulas, ya que al paso de las semanas y después los meses no lograban adaptarse a las sesiones en línea y deseaban ansiosos el regreso a presencial.

Es importante mencionar que justo en fechas cercanas a las graduaciones, había incertidumbre, inconformidades e incluso decepción, porque los alumnos querían "vivir" ese momento que desearon por casi 5 años de su preparación profesional, el recibir el papel que los distinguiría como pasantes de la licenciatura, pero sobre todo ese reconocimiento caluroso y afectuoso de familiares, amigos, compañeros y docentes, por haber logrado el sueño más anhelado para los estudiantes universitarios.

Actualmente, los estudiantes al escuchar esta noticia del regreso a clases voluntario, empezaron a generar especulaciones, pues ahora la incertidumbre es el regresar o no. Cada estudiante vivió procesos distintos en esta pandemia; desde el contagio de conocidos, hasta la pérdida de un ser querido que marco un rumbo distinto a para su vida. Por lo tanto y cómo se ha mencionado anteriormente las universidades deben generar programas de apoyo y así recuperar la confianza para el regreso de sus estudiantes.

Debido a las principales respuestas negativas que se pueden presentar ante este retorno presencial como lo es el estrés académico, docente, familiar entre otros se deberá fomentar una estrategia que permita disminuir los síntomas y su relación del estudiante ante la adaptación nuevamente de un espacio físico y reanudar sus rutinas cotidianas, pero con restricciones sanitarias, ya que si no hay una intervención oportuna sobre la sintomatología del estrés este puede conllevar a serios problemas que evolucionan en trastorno por estrés agudo, trastorno de estrés postraumático, trastorno de ansiedad, trastorno depresivo hasta llegar al abuso de alcohol y sustancias.

Por lo tanto, dentro de las medidas que se deben tener en cuenta ante el retorno presencial dentro de las instituciones de educación superior para el 
Instituto Internacional de Investigación y Desarrollo Tecnológico Educativo INDTEC, C.A.

DOI: https://doi.org/10.29394/Scientific.issn.2542-2987.2021.6.21.13.252-266

OAI-PMH: http://www.indteca.com/ojs/index.php/Revista Scientific/oai

Ensayo Original / Original Essay

personal que se tiene a cargo, es la brindar apoyo socioemocional y cuidar el aspecto mental, siendo una tarea ardua para los directivos quienes deben fomentar la participación con expertos en el área de salud, brindando estos servicios para un buen desempeño durante el ciclo escolar, conforme a Cobo, Vega y García (2020):

[...] Las universidades podrían valerse de unidades organizacionales como departamentos de bienestar estudiantil, psicología y orientación como espacios diseñados para la promoción de la salud mental en el contexto universitario tomando acciones en planes de intervención, asistencia o asesoramiento educativo para el desarrollo de sanas trayectorias educativas que den cuenta de los requisitos universitarios a la par de las necesidades contextuales de formación (pág. 281).

Finalmente, es necesario que las modificaciones tanto de estructuras físicas en las instituciones educativas de educación superior, y las adaptaciones implementadas para los actores sociales de la educación, permitan un retorno presencial seguro, en el cual se brinden los recursos necesarios para evitar propagación de nuevos casos de COVID-19.

Por lo cual, es necesario dar seguimiento a casos particulares que se detecten con poco apego a las clases presenciales y afecte su desempeño educativo, además de tener en cuenta las actualizaciones del semáforo epidemiológico a los cambios de color pueden variar por el surgimiento de nuevos casos o modificación de la cepa del virus, por lo que se debe hacer énfasis en que aún hay probabilidades de seguir implementados procesos educativos virtuales.

\section{Conclusiones}

Debido al brote del virus COVID-19 en México se emite un acuerdo por parte de las autoridades educativas en el cual se debe hacer un cierre de las instituciones de educación en todos sus niveles para evitar su propagación, 
por lo cual se decide llevar a cabo el proceso de enseñanza-aprendizaje en la modalidad virtual con el uso de plataformas digitales.

Ante el periodo de aislamiento ocasionado por la pandemia, las instituciones educativas se han visto afectadas en su estructura física, ya que con el pasar del tiempo se han descuidado estos espacios físicos, por lo que requieren una pronta intervención para su modificación estructural acorde a o a las medidas sanitarias que se han puesto en marcha para evitar más contagios ante tal regreso semipresencial por parte de los actores sociales de la educación.

Las universidades al ser instituciones autónomas tienen el privilegio para decidir e implementar medidas específicas acorde a sus necesidades actuales y bajo supervisión de sus consejos técnicos, por lo tanto se tiene establecido para algunas instituciones el retorno presencial durante mes de junio, siendo de una forma escalonada y voluntaria para la realización de prácticas profesionales, exámenes u alguna actividad que requiera la presencia del alumnado pero que a la vez se respeten estas medidas sanitarias o en su caso seguir con la modalidad a distancia si es que su personal docente aun no cuenta con la vacuna.

La salud mental es una prioridad ante tal regreso a clases presenciales para los docentes y alumnos, los cuales fueron afectados durante el aislamiento social en el aspecto mental, físico y social con repercusiones tales como estrés, ansiedad, depresión y sin alguna intervención durante este posible retorno a las universidades evoluciona en trastornos mentales para estos actores de la educación.

Los docentes al presentar cargas excesivas de trabajo también repercuten en su salud mental evidenciado mediante estrés laboral y académico siendo necesario el apoyo socioemocional para así poder hacer frente a las posibles situaciones de emociones negativas que van a presentar sus estudiantes ante las aulas físicas y este debe ser capaz de identificar y 
colaborar con expertos para ayudar al proceso de afrontamiento en sus alumnos que persistan con sintomatología que no remite.

Ante la posibilidad de un rebrote del virus COVID-19 y los cambios del semáforo epidemiológico, tal vez es una acción adelantada para el retorno presencial a las universidades y aunque se cumplan las medidas sanitarias se debe reconsiderar las posibilidades de seguir con la educación virtual y su vez la integración de apoyos y programas a la salud mental mediante plataformas virtuales de salud, sin la necesidad de arriesgar a la población estudiantil y docente.

\section{Referencias}

Alarcón, R. (2019). La Salud Mental de los estudiantes universitarios. Revista Médica Herediana, 30(4), 219-221, e-ISSN: 1729-214X. Recuperado de: https://doi.org/10.20453/rmh.v30i4.3655

Cobo-Rendón, R., Vega-Valenzuela, A., \& García-Álvarez, D. (2020). Consideraciones institucionales sobre la Salud Mental en estudiantes universitarios durante la pandemia de Covid-19. CienciAmérica, 9(2), 277-284. ISSN 1390-9592. Recuperado de: http://dx.doi.org/10.33210/ca.v9i2.322

Cuenca, N., Robladillo, L., Meneses, M., \& Suyo-Vega, A. (2020). Salud mental en adolescentes universitarios latinoamericanos: Revisión sistemática. AVFT: Archivos Venezolanos de Farmacología y Terapéutica, 39(6), 689-695, e-ISSN: 0798-0264. Venezuela: Sociedad Latinoamericana de Hipertension.

Medina-Guillen, L., Quintanilla-Ferrufino, G., Palma-Vallejo, M., \& Medina, M. (2021). Carga laboral en un grupo latinoamericano de docentes durante la pandemia de COVID-19. Uniciencia, 35(2), 1-14, e-ISSN: 2215-3470. Recuperado de: https://doi.org/10.15359/ru.35-2.15

Pinargote-Baque, K., \& Cevallos-Cedeño, A. (2020). El uso y abuso de las 
Instituto Internacional de Investigación y Desarrollo Tecnológico Educativo INDTEC, C.A.

DOI: $h$ ttps://doi.org/10.29394/Scientific.issn.2542-2987.2021.6.21.13.252-266

OAI-PMH: http://www.indteca.com/ojs/index.php/Revista Scientific/oai

Ensayo Original / Original Essay

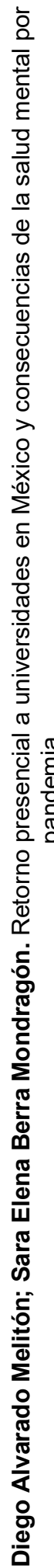

nuevas tecnologías en el área educativa. Dominio de las Ciencias, 6(3), 517-532, e-ISSN: 2477-8818. Recuperado de:

https://dialnet.unirioja.es/servlet/articulo?codigo $=7539716$

SEP (2020). Acuerdo número 02/03/20. Ciudad de México: Secretaría de Educación Pública. 


\section{Ensayo Original / Original Essay}

Diego Alvarado Melitón

e-mail: ocupacional fray@outlook.com

Nacido en Toluca, estado de México, el 12 de marzo del

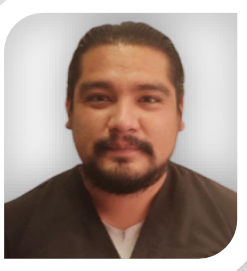
año 1989. Egresado de la Universidad Autónoma del estado de México (UAEM), con el título de licenciado en terapia ocupacional; y con una Maestría en docencia para nivel superior en la Universidad Tres Culturas (UTC); actualmente me desempeño como licenciado en terapia ocupacional en el manejo de pacientes psiquiátricos del Hospital Psiquiátrico Fray Bernardino Álvarez (HPFBA). 


\section{Ensayo Original / Original Essay}

\section{Sara Elena Berra Mondragón \\ e-mail: sara.berra@doc.utc.mx}

Nacida en Toluca, estado de México el 11 de

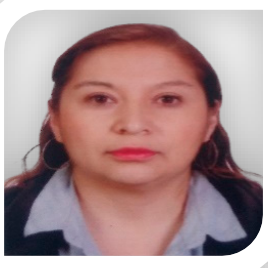
noviembre del año 1983. Egresada del Campus Universitario Siglo XXI, incorporado a la Universidad Autónoma del Estado de México (UAEM), con el título de la licenciatura en Administración; realizó sus estudios de Maestría en Docencia de Educación Superior por la Universidad Tres Culturas (UTC); actualmente me desempeño como docente en la Universidad Tres culturas; he colaborado en el Colegio de Educación Profesional Técnica (CONALEP) como Docente; en City Banamex, como capacitador en el área de Front Line y Asesor financiero; en Plenitud Mexiquense, A.C. como Socia y secretaría general; soy encargada de la administración de recursos financieros, recaudación de donaciones y relaciones públicas; además de administrar un negocio familiar dedicado a la comercialización de materiales para la construcción.

El contenido de este manuscrito se difunde bajo una Licencia de Creative Commons ReconocimientoNoComercial-Compartirlgual 4.0 Internacional 